\title{
The Role of Sonographic Markers of Ovarian Morphology Versus Hirsutism Indices in the Prediction of Serum Total Testosterone in Hirsute Women
}

\author{
Mohamed Tawfik Gad Al-Rab ${ }^{1}$, Emad Mossa Ibrahim ${ }^{1}$, Momen Mohamed Hassan ${ }^{1}$, Ayman Moheb ${ }^{2}$, Essia Mahmod \\ Khalefia ${ }^{2}$, Nashwa Mohamed Adel $^{3}$, Mostafa Ahmed El Sayed ${ }^{4}$ and Dina Hisham Hussain Emam Abdallah ${ }^{2 *}$ \\ ${ }^{1}$ Faculty of Medicine, Minia University, Egypt \\ ${ }^{2}$ Department of Obstetrics \& Gynecology, Minia University, Egypt \\ ${ }^{3}$ Department of Radiology, Minia University, Egypt \\ ${ }^{4}$ Department of clinical Pathology, Minia University, Egypt
}

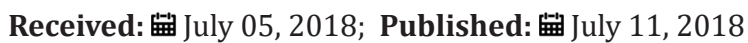

*Corresponding author: Dina Hisham Hussain Emam Abdallah,Department of Obstetrics \& Gynecology, Minia University, Egypt

\section{Abstract}

Objective: To evaluate the role of sonographic markers of ovarian morphology versus hirsutism indices in the prediction of serum total testosterone in hirsute women.

Study Design: Cross sectional observational Study.

Subjects: Eighty women (aged 18 to 40 years) form among the attendants of the Gynecology Clinic of Minia University Hospital complaining of hirsutism were recruited into the Study in the period between January and May 2017 after obtaining their informed consent.Participants were evaluated regarding self-reported menstrual cycle history to determine the extent of any menstrual cycle disturbance; male-pattern hair growth was assessed on nine regions of the body using the modified Ferriman-Gallwey (mFG) scoring system, a transvaginal ultrasound scan to characterize ovarian morphology and fasting blood sample for testosterone assay.

Main Outcome Measures: Regional and total modified Ferriman-Gallwey (mFG) scores, number of follicles per follicle size category, follicle number per ovary (FNPO), ovarian volume (OV), ovarian area (OA), stromal to ovarian area ratio (S/A), stromal echogenicity index (SI), total testosterone (TT) and menstrual cycle length.

Results: There were no correlations between any of the demographic characteristics of the study participants and total testosterone.There were no correlations between hirsutism scores and total testosterone of all study participants. However, there were some association between hirsutism scores (upper lip, chin and lower abdomen) and total testosterone of all study participants.

There were correlations between the three ovarian dimensions, ovarian volume, ovarian area, stromal echogenicity and ovarian echogenicity and total testosterone. However, there were no correlations between 2-5mm FNPO, 6-9mm FNPO, 2-9mm FNPO, stroma to ovary ratio \& stromal echogenicity index and total testosterone.

Conclusion: Sonographic markers particularly ovarian dimensions, ovarian volume, ovarian area, stromal echogenicity and ovarian echogenicity are good predictors of total testosterone levels in women with hirsutism whether having regular or irregular menstrual cycles.They are better predictor of total testosterone levels than other Sonographic markers namely number of follicles of different sizes, stroma to ovary ratio and stromal echogenicity index. They are much more sensitive predictors of total testosterone than hirsutism scores whether regional or total scores.

Keywords: Hirsutism;Vaginal sonography;Ovaries;Testosterone; Menstrual cycle

Abbreviations: mFG: Ferriman-Gallwey; FNPO: Follicle Number Per Ovary; OV: Ovarian Volume; OA: Ovarian Area; S/A: Stromal to ovarian Area ratio; SI: Stromal echogenicity Index; TT: Total Testosterone 


\section{Introduction}

Commercial assays for serum testosterone ( $\mathrm{T}$ ) yield inconsistent results [1,2], whereas direct measurements of free T are technically challenging [3] and influenced by metabolic status [4,5]. Given these challenges in biochemical assessments of androgens in women, additional measures to evaluate androgen status are practically needed [2].Male-pattern hair growth is the most commonly accepted clinical indicator of androgen status [6]. Atypical hair growth is commonly quantified using the modified FerrimanGallwey [7](mFG) scoring system, which rates hair growth on nine androgen-sensitive regions of the body using a 0-4 scale. The utility of all nine regions in the prediction of androgen excess remains a topic of debate [8,9]. This notion has merit because a more focused approach involving a subset of regions with the greatest sensitivity to androgen levels could help to obviate some of the subjectivity associated with hirsutism scoring [10,11].

Uncertainty in the utility of hirsutism scores stems from findings of poor agreement in hirsutism scores [12,13], as well as the known influence of age [14], race and ethnicity $[15,16]$ and adiposity [12,13] on male-pattern hair growth. Although hirsutism has shown better sensitivity for biochemical hyperandrogenism compared with acne or alopecia $[17,18]$, its specificity is low because idiopathic hirsutism occurs in $5 \%-15 \%$ of the general population [19] and in up to $50 \%$ of all mild hirsutism cases studied [20]. The advent of more standardized approaches to measure serum androgens provides an opportunity to revisit the utility of hirsutism scores to reflect androgen levels.In view of the improved resolution afforded by the latest imaging systems [21-23], there is growing evidence supporting an expanded role for ovarian ultrasonography in the clinical evaluation of androgen excess [24].
The objective of this study was to assess the ability of sonographic markers of ovarian morphology versus $\mathrm{mFG}$ scores to predict total testosterone (T) levels in women. In this study, we enrolled women with hirsutism and then divide them regarding to their cycle regularity to assess any impact of menstrual cycle status on these relationships. We tried to test the hypnosis whether sonographic markers or hirsutism indices would be more predictive to the testosterone levels in hirsute women.

\section{Results}

Table 1 shows the Correlation between demographic characteristics and total testosterone of the study participants with regular and irregular menstrual cycles, there were no correlation between any of the demographic characteristics in either of the two groups and Total Testosterone. Table 2 shows the correlation between hirsutism scores and total testosterone of study participants with regular and irregular menstrual cycles. There was no correlation between any of the hirsutism score and total testosterone of study participants with regular and irregular menstrual cycles.Table 3 shows the correlation between sonographic markers and total testosterone of study participants with regular and irregular menstrual cycles. There were correlations between ovarian dimensions, ovarian volume, ovarian area, stromal echogenicity and ovarian echogenicity and total testosterone in both groups. However, there were no correlations between 2-5FNPO, 6-9 FNPO and 2-9 FNPO, stroma to ovary ratio \& stromal echogenicity index and total Testosterone in both groups. Table 4 shows the coloration between demographic characteristics and total testosterone of all study participants. There were no correlations between any of the demographic characteristics and total testosterone.

Table 1: Correlation between Demographic Characteristics and Total Testosterone of the study participants with regular and irregular menstrual cycles.

\begin{tabular}{|c|c|c|c|c|}
\hline \multicolumn{5}{|c|}{ Correlations } \\
\hline & \multicolumn{4}{|c|}{ T. Testosterone (ng/ml) } \\
\hline & \multicolumn{2}{|c|}{ Women with Regular Menstrual Cycles } & \multicolumn{2}{|c|}{ Women with Irregular Menstrual Cycles } \\
\hline & $\mathbf{r}$ & P-value & $\mathbf{r}$ & P-value \\
\hline Age & 0.254 & 0.119 & 0.073 & 0.664 \\
\hline Weight (KG) & 0.137 & 0.406 & 0.13 & 0.438 \\
\hline Height (CM) & 0.021 & 0.898 & 0.119 & 0.477 \\
\hline BMI (Kg/m2) & 0.168 & 0.306 & 0.069 & 0.684 \\
\hline Age of Menarche (Years) & 0.034 & 0.837 & 0.178 & 0.284 \\
\hline Cycle Length & 0.006 & 0.972 & . & . \\
\hline $\begin{array}{l}\text { Cycle Length Shortest } \\
\text { (Days) }\end{array}$ & . & . & -0.042 & 0.801 \\
\hline Cycle Length Longest (Days) & . & . & 0.059 & 0.724 \\
\hline
\end{tabular}


Table 2: Correlation between Hirsutism Scores and Total Testosterone of study participants with regular and irregular menstrual cycles.

\begin{tabular}{|c|c|c|c|c|}
\hline \multirow{2}{*}{} & \multicolumn{4}{|c|}{ Correlations } \\
\cline { 2 - 5 } & \multicolumn{3}{|c|}{ T. Testosterone (ng/ml) } \\
\cline { 2 - 5 } & Women with Regular Menstrual Cycles & \multicolumn{2}{|c|}{ Women with Irregular Menstrual Cycles } \\
\hline Upper lip & $\mathbf{r}$ & P-value & r & 0.185 \\
\hline Chin & 0.05 & 0.762 & 0.218 & 0.266 \\
\hline Chest & 0.21 & 0.199 & 0.207 & 0.183 \\
\hline Upper arm & 0.184 & 0.262 & 0.147 & 0.377 \\
\hline lower Abdomen & 0.002 & 0.992 & 0.117 & 0.485 \\
\hline upper Abdomen & 0.033 & 0.842 & 0.226 & 0.172 \\
\hline Upper Back & 0.259 & 0.112 & 0.296 & 0.072 \\
\hline Lower Back & 0.185 & 0.258 & 0.293 & 0.074 \\
\hline Thigh & 0.06 & 0.719 & 0.315 & 0.054 \\
\hline Total Score & 0.173 & 0.292 & 0.259 & 0.116 \\
\hline
\end{tabular}

Table 3: Correlation between Sonographic Markers and Total Testosterone of study participants with regular and irregular menstrual cycles.

\begin{tabular}{|c|c|c|c|c|}
\hline \multirow{2}{*}{} & \multicolumn{4}{|c|}{ Correlations } \\
\cline { 2 - 5 } & \multicolumn{3}{|c|}{ T. Testosterone (ng/ml) } \\
\cline { 2 - 5 } & Women with Regular Menstrual Cycles & \multicolumn{2}{c|}{ Women with Irregular Menstrual Cycles } \\
\hline $2-5 m m$ FNPO & $\mathbf{r}$ & P-value & r & 0.93 \\
\hline 6-9mm FNPO & 0.358 & 0.025 & 0.015 & 0.686 \\
\hline 2-9mm FNPO & 0.034 & 0.839 & 0.002 & 0.989 \\
\hline Axis 1 (CM) & 0.286 & 0.078 & 0.649 & $<0.001^{*}$ \\
\hline Axis 2 (CM) & 0.533 & $<0.001^{*}$ & 0.628 & $<0.001^{*}$ \\
\hline Axis 3 (CM) & 0.585 & $<0.001^{*}$ & 0.801 & $<0.001^{*}$ \\
\hline OV (CM3) & 0.804 & $<0.001^{*}$ & 0.869 & $<0.001^{*}$ \\
\hline OA (CM2) & 0.795 & $<0.001^{*}$ & 0.755 & $<0.001^{*}$ \\
\hline S/A ratio & 0.687 & $<0.001^{*}$ & 0.221 & 0.182 \\
\hline SE & 0.39 & 0.014 & 0.705 & $<0.001^{*}$ \\
\hline OE & 0.806 & $<0.001^{*}$ & 0.708 & $<0.001^{*}$ \\
\hline SEI & 0.683 & $<0.001^{*}$ & 0.013 & 0.94 \\
\hline
\end{tabular}

N.B Axis 1 indicates the transverse diameter of the ovary.

Axis 2 indicates the vertical diameter of the ovary.

Axis 3 indicates the antro-posterior diameter of the ovary.

Table 4: Correlation between Demographic Characteristics and Total Testosterone of all study participants.

\begin{tabular}{|c|c|c|}
\hline \multirow{2}{*}{ All Patients } & \multicolumn{2}{|c|}{ Correlations } \\
\hline & $\mathbf{r}$ & T. Testosterone (ng/ml) \\
\cline { 2 - 3 } & 0.112 & 0.331 \\
\hline Age & 0.136 & 0.240 \\
\hline Weight (KG) & 0.097 & 0.404 \\
\hline Height (CM) & 0.106 & 0.361 \\
\hline BMI (Kg/m2) & 0.259 & 0.023 \\
\hline Age of Menarche (Years) & & \\
\hline
\end{tabular}




\begin{tabular}{|c|c|c|}
\hline Cycle Length & 0.006 & 0.972 \\
\hline Cycle Length Shortest (Days) & 0.042 & 0.801 \\
\hline Cycle Length Longest (Days) & 0.059 & 0.724 \\
\hline
\end{tabular}

Table 5 shows the correlation between Hirsutism Scores and Total Testosterone of all study participants. There were no correlations between Hirsutism scores and Total Testosterone of all study participants. However, there were some association between Hirsutism scores (upper lip, chin and lower abdomen ( $\mathrm{r}$ of $\geq 0.3<0.5$ ) and Total Testosterone of all study participants. Table 6 shows the correlation between Sonographic Markers and
Total Testosterone of all study participants. There was correlation between the three ovarian dimensions, ovarian volume, Ovarian Area, stromal echogenicity and ovarian echogenicity and Total Testosterone. However, there were no correlations between 2-5mm FNPO, 6-9mm FNPO, 2-9mm FNPO, stroma to ovary ratio \& stromal echogenicity index and Total Testosterone.

Table 5: Correlation between Hirsutism Scores and Total Testosterone of all study participants.

\begin{tabular}{|c|c|c|}
\hline \multicolumn{3}{|c|}{ Correlations } \\
\hline \multirow{2}{*}{ All Patients } & \multicolumn{2}{|c|}{ T. Testosterone (ng/ml) } \\
\hline & $\mathbf{r}$ & P-value \\
\hline Upper lip & 0.391 & $<0.018$ \\
\hline Chin & 0.437 & $<0.016$ \\
\hline Chest & 0.095 & 0.412 \\
\hline Upper arm & 0.061 & 0.601 \\
\hline Lower Abdomen & 0.369 & 0.018 \\
\hline Upper Abdomen & 0.154 & 0.182 \\
\hline Upper Back & 0.163 & 0.158 \\
\hline Lower Back & 0.114 & 0.323 \\
\hline Thigh & 0.183 & 0.111 \\
\hline Total Score & 0.056 & 0.629 \\
\hline
\end{tabular}

Table 6: Correlation between Sonographic Markers and Total Testosterone of all study participants.

\begin{tabular}{|c|c|c|}
\hline \multirow{2}{*}{ All Patients } & \multicolumn{2}{|c|}{ Correlations } \\
\hline & $\mathbf{2}$ & \multicolumn{2}{c|}{ T. Testosterone (ng/ml) } \\
\cline { 2 - 3 } & 0.266 & 0.019 \\
\hline 2-5mm FNPO & 0.194 & 0.090 \\
\hline 2-9mm FNPO & 0.330 & $<.003$ \\
\hline Axis 1 (CM) & 0.803 & $<0.001^{*}$ \\
\hline Axis 2 (CM) & 0.790 & $<0.001^{*}$ \\
\hline Axis 3 (CM) & 0.853 & $<0.001^{*}$ \\
\hline OV (CM3) & 0.913 & $<0.001^{*}$ \\
\hline OA (CM2) & 0.871 & $<0.001^{*}$ \\
\hline S/A ratio & 0.488 & $<0.001$ \\
\hline SE & 0.809 & $<0.001^{*}$ \\
\hline OE & 0.749 & $<0.001^{*}$ \\
\hline SEI & 0.355 & 0.002 \\
\hline
\end{tabular}

N.B Axis 1 indicates the transverse diameter of the ovary.

Axis 2 indicates the vertical diameter of the ovary.

Axis 3 indicates the antro-posterior diameter of the ovary. 


\section{Discussion}

In this current Study, there were no correlation between any of the demographic characteristics in either of the regular and irregular cycle and Total Testosterone. These findings are in accordance with those ofVanden Brink $\mathrm{H}$ et al.[25], who did not find any correlation between age, weight, height, body mass index and total testosterone level in their study participants.In this current study, there were no correlation between any of the Hirsutism score and total testosterone of study participants with regular and irregular menstrual cycles. The findings regarding this issue are very controversial in the previous studies. Rashidi $\mathrm{H}$ et al. [14] mentioned that evaluating terminal hair growth on the chin or lower abdomen for predicting androgenism seems to be an acceptable screening method. Also, Ramezani Tehrani $\mathrm{F}$ et al. [26], stated that the three-area subset of lip, lower abdomen and thighs serves as a simple method of androgenism assessment and can be used in large epidemiologic studies. However, the findings of this current study and that of another recent study conducted by Vanden Brink H et al. [25] concluded that Hirsutism scores are not predictive for Total Testosterone levels. This actually seems more acceptable when considering that 5-15\% of women with hirsutism are idiopathic Melissa HH. and Peter JC [27]\&YildizBO et al.[28].

In this current Study, there were correlations between ovarian dimensions, ovarian volume, ovarian area, stromal echogenicity \& ovarian echogenicity and Total Testosterone in both groups. However, there were no correlations between 2-5FNPO, 6-9 FNPO and 2-9 FNPO, stroma to ovary ratio \& stromal echogenicity index and Total Testosterone in both groups. These findings agree with those of Vanden Brink H et al. [25]. This agreement was complete regarding women with irregular cycles. However, Vanden Brink H et al. [25] reported significant correlation between Total Testosterone and 6-9 FNPO. The small difference in results between our results and that of Vanden Brink H et al. [25] could be partially due to the fact that our participants were in general having mild degrees of Hirsutism. Also, our results were not in agreement with those of Fulghesu AM et al. [29] who reported that Stroma to ovary ratio was found to be the best significant predictor of elevated Testosterone level.

In this current Study, there were no correlations between any of the Demographic Characteristics of all study participants and Total Testosterone. These findings are in accordance with those of Vanden Brink $\mathrm{H}$ et al. [25], who did not find any correlation between age, weight, height, body mass index and Total Testosterone level in their study participants.In this current Study, there were no correlations between Hirsutism scores and Total Testosterone of all study participants. However, there were some association between Hirsutism scores (upper lip, chin and lower abdomen ( $\mathrm{rof} \geq 0.3<0.5$ ). These findings are in agreement with those of Vanden Brink $\mathrm{H}$ et al.[25] who noted that regional $\mathrm{mFG}$ scores were more predictive of total testosterone compared to the total $\mathrm{mFG}$ score. However, neither regional nor total $\mathrm{mFG}$ scores predicted total testosterone to any significant degree in either women with regular or irregular menstrual cycles. Our results are not completely in agreement with Api Met al. [8] who concluded that the mFG scoring system was found to be clinically useful and the upper lip was observed to have the highest score of androgen sensitive area of the body as well as the highest inter-observer variability and that the cut-off value to establish the diagnosis of hirsutism should be population-specific. Also, our results are not completely in agreement with Rashidi $\mathrm{H}$ et al. [14] who concluded that evaluating terminal hair growth on chin or lower abdomen for predicting hirsutism seems to be an acceptable screening method.

In this current Study, there were correlation between the three ovarian dimensions, ovarian volume, ovarian area, stromal echogenicity and ovarian echogenicity in all study participants and Total Testosterone. However, there were no correlations between 2-5mm FNPO, 6-9mm FNPO, 2-9mm FNPO, stroma to ovary ratio \& stromal echogenicity ratio index and Total Testosterone. Our results were not in agreement with those of Fulghesu AM et al. [29], who reported that Stroma to ovary ratio was found to be the best significant predictor of elevated Testosterone level. However, our results are more in agreement with those of Vanden Brink $\mathrm{H}$ et al.[25] who concluded that sonographic markers may serve as a clinical biomarker for androgen status in instances where access to high-performance assays is more limited. The ability of ovarian morphology to predict total testosterone levels was modified by menstrual cycle status and that their findings support the use of ultrasonography as a potentially informative tool in the detection of hyperandrogenemia in women with regular menstrual cycles, where other clinical indicators of androgen excess may not necessarily be present.

\section{References}

1. Moal V, Mathieu E, Reynier P, Malthiery Y, Gallois Y (2007) Low serum testosterone assayed by liquid chromatography-tandem mass spectrometry. Comparison with five immunoassay techniques. ClinChimActa 386(1-2): 12-19.

2. Rosner W, Auchus RJ, Azziz R, Sluss PM, Raff H (2007) Position statement: Utility, limitations, and pitfalls in measuring testosterone: An Endocrine Society position statement. J ClinEndocrinolMetab 92(2): 405-413.

3. Miller KK, Rosner W, Lee H, Hier J, Sesmilo G, et al. (2004) Measurement of free testosterone in normal women and women with androgen deficiency: comparison of methods. J ClinEndocrinolMetab 89(2): 525533.

4. Pugeat M, Crave JC, Elmidani M, Nicolas MH, Garoscio-Cholet M, et al. (1991) Pathophysiology of sex hormone binding globulin (SHBG): relation to insulin. J Steroid BiochemMol Bio 40(4-6): 841-849.

5. Cupisti S, Dittrich R, Binder H, Kajaia N, Hoffmann I, et al. (2007) Influence of body mass index on measured and calculated androgen parameters in adult women with hirsutism and PCOS. ExpClinEndocrinol Diabetes 115(6): 380-386.

6. Azziz R, Sanchez LA, Knochenhauer ES, Moran C, Lazenby J, et al. (2004) Androgen excess in women: experience with over 1000 consecutive patients. J ClinEndocrinolMetab 89(2): 453-462.

7. Ferriman D, Gallwey JD (1961) Clinical assessment of body hair growth in women. J ClinEndocrinolMetab 21: 1440-1447. 
8. Api M, Badoglu B, Akca A, Api O, Gorgen H, et al. (2009) Interobserver variability of modified Ferriman-Gallwey hirsutism score in a Turkish population. Arch Gynecol Obstet 279(4): 473-479.

9. Cook H, Brennan K, Azziz R (2011) Reanalyzing the modified FerrimanGallwey score: is there a simpler method for assessing the extent of hirsutism? FertilSteril 96(5): 1266-1270.

10. Derksen J, Moolenaar AJ, Van Seters AP, Kock DF (1993) Semiquantitative assessment of hirsutism in Dutch women. Br J Dermatol 128(3): 259263.

11. Hines G, Moran C, Huerta R, Folgman K, Azziz R (2001) Facial and abdominal hair growth in hirsutism: a computerized evaluation. J Am AcadDermatol 45(6): 846-850.

12. Clark NM, Podolski AJ, Brooks ED, Chizen DR, Pierson RA, et al. (2014) Prevalence of Polycystic Ovary Syndrome Phenotypes Using Updated Criteria for Polycystic Ovarian Morphology: An Assessment of Over 100 Consecutive Women Self-reporting Features of Polycystic Ovary Syndrome. Reprod Sci 21(8): 1034-1043.

13. Kiddy DS, Sharp PS, White DM, Scanlon MF, Mason HD, et al. (1990) Differences in clinical and endocrine features between obese and nonobese subjects with polycystic ovary syndrome: an analysis of 263 consecutive cases. ClinEndocrinol 32(2): 213-220.

14. Rashidi H, Parizi ZT, Mohammadi M (2013) Evaluation of only the chin or lower abdomen for predicting hirsutism. Indian J EndocrinolMetab 17(5): 896-898.

15. Escobar-Morreale HF, Carmina E, Dewailly D, Gambineri A, Kelestimur F, et al. (2012) Epidemiology, diagnosis and management of hirsutism: a consensus statement by the Androgen Excess and Polycystic Ovary Syndrome Society. Hum Reprod Update 18(2): 146-170.

16. Javorsky E, Perkins AC, Hillebrand G, Miyamoto K, Boer Kimball A (2014) Race, rather than skin pigmentation, predicts facial hair growth in women. J ClinAesthetDermatol 7(5): 24-26.

17. Azziz R (2003) The evaluation and management of hirsutism. Obstet Gynecol 101(5): 995-1007.

18. Karrer-Voegeli S, Rey F, Reymond MJ, Meuwly JY, Gaillard RC, et al. (2009) Androgen dependence of hirsutism, acne, and alopecia in women: retrospective analysis of 228 patients investigated for hyperandrogenism. Medicine 88(1): 32-45.
19. Yildiz BO, Bolour S, Woods K, Moore A, Azziz R (2010) Visually scoring hirsutism. Hum Reprod Update 16(1): 51-64.

20. Reingold SB, Rosenfield RL (1987) The relationship of mild hirsutism or acne in women to androgens. Arch Dermatol 123(2): 209-212.

21. Jayaprakasan K, Campbell BK, Clewes JS, Johnson IR, Raine-Fenning NJ (2008) Three-dimensional ultrasound improves the interobserver reliability of antral follicle counts and facilitates increased clinical work flow. Ultrasound Obstet Gynecol 31(4): 439-444.

22. Lujan ME, Brooks ED, Kepley AL, Chizen DR, Pierson RA, et al. (2010) Grid analysis improves reliability in follicle counts made by ultrasonography in women with polycystic ovary syndrome. Ultrasound Med Biol 36(5): 712-718.

23. Lujan ME, Chizen DR, Peppin AK, Kriegler S, Leswick DA, et al (2008) Improving inter-observer variability in the evaluation of ultrasonographic features of polycystic ovaries. Reprod Biol Endocrinol 6: 30 .

24. Christ JP, Willis AD, Brooks ED, Vanden Brink H, Jarrett BY, et al (2014) Follicle number, not assessments of the ovarian stroma, represents the best ultrasonographic marker of polycystic ovary syndrome. FertilSteril 101(1): 280-287.

25. Vanden Brink H, Willis AD, Jarrett BY, Lin AW, Soler S, et al. (2016) Sonographic markers of ovarian morphology, but not hirsutism indices, predict serum total testosterone in women with regular menstrual cycles. FertilSteril 105(5): 1322-1329.

26. Ramezani Tehrani F, Minooee S, Azizi F (2014) Validation of a simplified method to assess hirsutism in the Iranian population. Eur J Obstet Gynecol Reprod Biol 174: 91-95.

27. Melissa HH, Peter JC (2003) Evaluation and Treatment of Women with Hirsutism. Am Fam Physician. Jun 15 67(12): 2565-2572.

28. Yildiz BO, Bolour S, Woods K, Moore A, Azziz R (2010) Visually scoring hirsutism. Hum Reprod Update 16(1): 51-64.

29. Fulghesu AM, Angioni S, Frau E, Belosi C, Apa R, et al. (2007) Ultrasound in polycystic ovary syndrome-the measuring of ovarian stroma and relationship with circulating androgens: results of a multicentric study. Hum Reprod 22(9): 2501-2508.

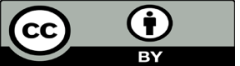

This work is licensed under Creative Commons Attribution 4.0 License

Submission Link: Submit Article

DOI: $10.32474 /$ OAJRSD.2018.01.000110

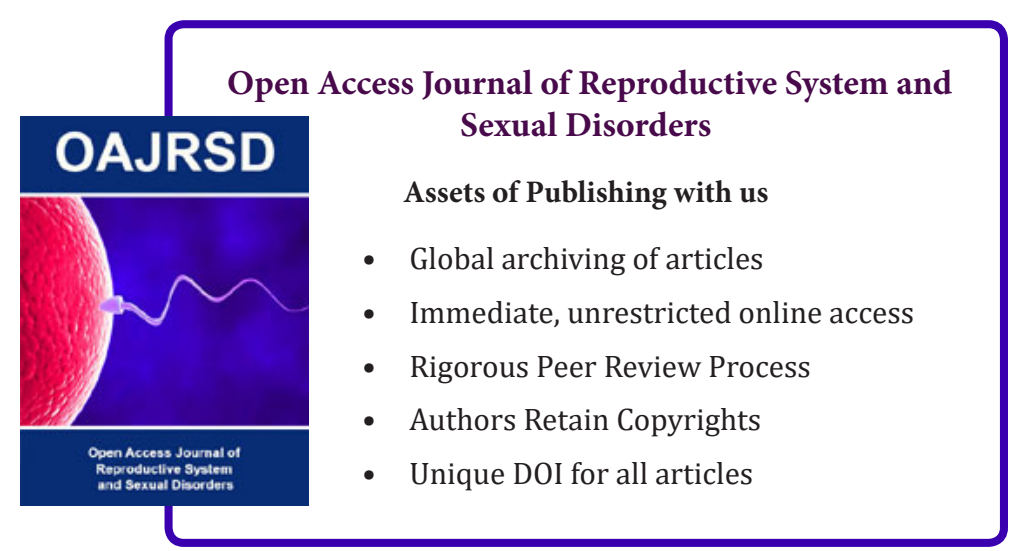

